\title{
Long-term results after the modified Ravitch procedure performed in children and adolescents - a one-time procedure without the need to use additional support of the sternum. A retrospective study
}

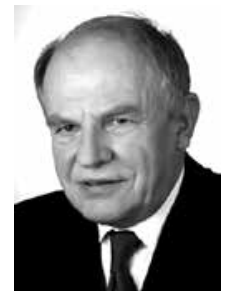

\author{
Joachim Buchwald ${ }^{1}$, Dariusz Ligarski ${ }^{1}$, Tomasz Polewczyk ${ }^{2}$ \\ ${ }^{1}$ Department of Thoracic Surgery, Institute of Tuberculosis and Lung Diseases, Rabka-Zdrój, Poland \\ ${ }^{2}$ Department of Radiology, Institute of Tuberculosis and Lung Diseases, Rabka-Zdrój, Poland
}

Kardiochir Torakochir Pol 2020; 17 (4): 173-177

\begin{abstract}
Introduction: Pectus excavatum is a depression of the sternum. Pectus carinatum, in contrast, is the convexity of the sternum. The mixed form is an intermediate condition. Surgical intervention is the treatment of choice. The techniques most commonly used include the Ravitch and the Nuss procedures.

Aim: To assess the immediate and long-term results of the original modification of the surgical treatment for anterior chest wall deformation.

Material and methods: The modification is based on the Ravitch procedure. The difference is that the ends of the resected cartilages are shaped like a blade in order to be inserted into the previously prepared wedge-shaped hollows located on both edges of the sternum. The result is long lasting without the need to use additional brackets.

Results: The follow-up examinations performed in 72 patients, including 57 boys and 15 girls, were the basis to produce longterm results. As for the type of deformity, out of 57 patients operated on due to pectus excavatum, 43 expressed satisfaction with the very good result. Similar satisfaction was reported in 7 out of 11 patients operated on due to pectus carinatum. There were 4 cases with the mixed form who had very good long-term results. Wound dehiscence was observed in 13 subjects, with one documented recurrence.

Conclusions: The alternative treatment we propose is a one-time procedure without the need to use additional support of the sternum. Good long-term results make the procedure suitable to be used more frequently in all types of deformities.
\end{abstract}

Key words: pectus excavatum, pectus carinatum, mixed form, Kopera-Krol index.

\section{Introduction}

The first descriptions of pectus excavatum date back to the end of the $15^{\text {th }}$ century. Five centuries later, in 1911, the first publications of corrective surgical treatment of this deformity appeared [1]. Surgical techniques are changing, but the aetiology remains unknown. Although there is insufficient evidence to determine the causes of the defect, the Ochsner hypothesis of 1939 gained recognition. The causes of a pathological depression of the sternum are sought in the accelerated, disproportionate growth of the costal cartilages in relation to the remaining bone skeleton. As a consequence, the sternum is pressed towards the spine [2]. This belief changed operating techniques. Ravitch was the first to describe this procedure in 1949 [1]. The method involves bilateral excision of the deformed costal cartilages in order to activate the sternum and perform transverse wedge osteotomy. The procedure allows for rotation of the sternum to the intended position fixed with mattress sutures which bring the opposite edges of the osteotomy closer. Thus, the sternum rises to the front and stabilization becomes possible even without the implantation of foreign bodies. However, in most cases, long-lasting and safe operative reposition of the sternum is possible with the use of various foreign bodies that have to be removed. The procedures are based on autologous rib grafts or wedge cartilage resections performed on the surfaces of the deformed cartilages, including the aforementioned metal structures and plastic restorations [3-7].

A minimally invasive surgical technique, called the Nuss procedure, named after its author, is gaining more and more popularity in the treatment of anterior chest wall defects [8]. Skin cuts of several centimetres made on the

Address for correspondence: Joachim Buchwald, Department of Thoracic Surgery, Institute of Tuberculosis and Lung Diseases, Rabka-Zdrój,

Poland, e-mail: jbuchwald42@gmail.com

Received: 10.09.2020, accepted: 15.11.2020. 
lateral walls of the chest allow for the introduction and removal of a previously shaped metal plate from the pleural cavities. A degree of deformation determines the number of plates to be used; they are formed appropriately depending on the expected shape of the anterior chest wall. The videothoracoscopic camera monitors movements made in the pleural cavity, and above all, the correct positioning of the implanted rod behind the posterior wall of the sternum. Rotation of the rod by $180^{\circ}$ pushes the depressed sternum forward, reducing deformation. Special stabilizers protect implants against unintentional, uncontrolled rotation.

The incidence of pectus carinatum is much lower [9]. The symptoms are scarce, but produce an enormous emotional burden, leading to anxiety, fear and pathological behaviours aimed at concealing the abnormality.

The mixed form has not been precisely defined because the elements of the concavity and convexity of the anterior chest wall bone skeleton coexist [9].

\section{Aim}

The aim of the study is to assess the immediate and long-term results of the original modification of the surgical treatment for anterior chest wall deformation.

\section{Material and methods}

Retrospective data from the medical records of 98 patients with anterior chest wall deformity were documented from January 2015 to December 2017. The patients were operated on at the Department of Thoracic Surgery of the Institute of Tuberculosis and Lung Diseases in the Unit in Rabka Zdroj. The data generated from a computer system and based on the International Classification of Diseases (Q67.6 and Q67.7) were used in follow-up examinations performed about one year after the surgery [10].

The degree of deformity in patients with pectus excavatum was calculated using the Kopera-Krol index (KK), which is the ratio of the greatest to the smallest distance between the posterior surface of the sternum and the anterior surface of the spine measured on lateral chest X-rays. The quotient of these two quantities is a basis for a three-point scale: grade I with the K-K values from 1 to 1.1 , grade II with the values ranging from 1.1 to 1.3 , and grade III > 1.3 [11].

The main indications for surgical intervention were mainly emotional factors expressed timidly and with some embarrassment; they were also revealed when the patient was asked to show the defect during a physical examination. Routine pre-operative preparations were preceded by educational sessions with the patients and their caregivers. All the questions about the operation were answered and any doubts were dispelled. The patients were asked to follow strict principles immediately before the operation, but more importantly after the procedure. These are simple and easy-to-follow rehabilitation duties, with the most important rule of maintaining the correct body posture with the shoulder girdle abducted.

For the Ravitch procedure, the patients received general anaesthesia, alone or combined with thoracic epidural an- aesthesia - an epidural catheter was placed in the Th6-Th8 intervertebral space. The general and epidural anaesthesia protocols were described by our colleagues in the previous study [12].

Regardless of the degree of deformation, the course of oblique skin incision on the surface of the sternum was determined by points marked symmetrically in relation to the nipples. This action is necessary to achieve a good aesthetic postoperative effect, with this incision line. Dissected pectoral muscles disclose the plane of the sternum with the sections of full-size deformed cartilage. The xiphoid process is cut off. Then, the intercostal muscle attachments are delaminated in order to radically cut out chondro-costal sections with an incorrect shape and course. However, during the entire procedure we must keep our eyes on the possible outcomes of the reconstruction. The number of excised cartilages depends on a degree of the sternum depression. It usually ranges from the $2^{\text {nd }}$ or $3^{\text {rd }}$ to the $7^{\text {th }}$ costal cartilage. The resulting parasternal cartilage stumps are dissected from the sternum, which is formed to give a physiological shape. The released sternum becomes susceptible to manual modelling, usually bent upwards, often to the sides, in order to eliminate the pathological angular position. On the lateral edges, wedge-shaped hollows are formed. The peripheral cartilage ends, which are shaped like a blade, are inserted into the wedge-shaped hollows created between the laminae of the sternum using single, non-absorbable polyester knotted sutures. Each suture covers the thickness of the sternum and distal sections of the costal cartilages. This is illustrated in Figure 1. This way, a natural support is formed which holds the sternum in a coordinated position. At the level of the lower pole of the surgical wound, a drain is left; it is led out from the anterior mediastinum. If a mediastinal pleural tear happens during preparation the complication, called pneumothorax, is eliminated by introducing a draining catheter into the pleural cavity. The pectoral muscles are brought closer together using single knotted sutures, each of them being guided through the scaffolding of the sternocartilaginous sutures already present on both edges of the sternum. This is shown on the left edge of the sternum in Figure 1. The natural shape of the anterior chest wall is restored without the need to use additional brackets. The procedure ends with application of a continuous subcutaneous suture.

Postoperative pain management included epidural infusion of the local anaesthetic with opioid $(0.2 \%$ ropivacaine or $0.125 \%$ bupivacaine with fentanyl $5 \mu \mathrm{g} / \mathrm{ml}(0.1 \mathrm{ml} / \mathrm{kg} / \mathrm{h}))$ or intravenous infusion of morphine $(20-50 \mu \mathrm{g} / \mathrm{kg} / \mathrm{h})$. The patients also received, irrespective of the type of postoperative analgesia, non-opioid painkillers, such as paracetamol, a non-steroidal anti-inflammatory drug and metamizole as a "rescue drug". In smaller children $<7$ years old, postoperative pain intensity was measured using the FLACC scale and the Numerical Rating Scale (NRS) in older children [13]. In both cases, the scale range was $0-10$ points ( 0 - no pain; 10 - worst possible pain). Pain intensity was measured by nurses according to the three-step method (i.e. at rest, during deep breathing and when coughing), which was devel- 
oped in our department and described by Tomaszek et al. $[12,14]$. The therapeutic goal of pain control was to reduce pain intensity during coughing to no more than 2 points.

The assessment of long-term results of thoracoplasty (a year after surgery) took into account the consequences of surgery, shape and symmetry of the surgically changed contours of the anterior chest wall and the appearance of the postoperative scar. We also took into account the patient's self-evaluation of the result, i.e. full satisfaction, approval of the effect or dissatisfaction. This allowed us to group the subjects into three categories:

- Very good result, when the effect of reconstruction met the expectations of the patient and operator i.e. restoration of the expected shape of the anterior chest wall with a linear scar and symmetry.

- Good result expressed by all the parties, i.e. the patient and operator, although the result was different than expected, either because of persistent retraction or secondary changes in the scar.

- Finally, a group of dissatisfied patients, with a mediocre long-term result, the lack of noticeable clinical improvement and the consequent dissatisfaction.

\section{Statistical analysis}

Continuous data are presented as a median, upper and lower quartile. Categorical data are shown as number or percentage. The assumption of normality was checked using the Shapiro-Wilk test. Differences between the two dependent samples (K-K before vs. K-K after pectus excavatum surgery) were assessed using the non-parametric Wilcoxon test. Statistical analysis was performed using the Statistica 13 program (StatSoft, Poland). The significance level was set at 0.05 .

\section{Results}

Ninety-eight patients were evaluated for enrolment in the study. Twenty-six (26.5\%) patients did not report to the follow-up visit. The data of the remaining 72 patients was included in the final analysis. There were 57 (79.2\%) boys and $15(20.8 \%)$ girls in the cohort. In the group of boys, the median was 14.6 years, and in the group of girls almost 13 years. The youngest of the operated patients was 4.5 years old and the oldest was just over 18. As for the type of deformity, there were 57 patients with pectus excavatum (79.2\%), including 13 subjects with the advanced form of the disease confirmed by the objective measurement with the K-K index. Then, there were 11 (15.3\%) patients with pectus carinatum and the last group of 4 (5.5\%) cases with the mixed form. In most cases, i.e. 54 (75.0\%), the operations were performed under general anaesthesia combined with thoracic epidural anaesthesia. During the remaining 18 (25.0\%) operations, only general anaesthesia was used. The median duration of thoracic surgery was $130(115 ; 145)$ minutes. The patient was discharged when his/her clinical condition was good, and this was supported by the results of laboratory and imaging tests, as well healing of the surgical wound. In the absence of complications, the patients were hospitalized for

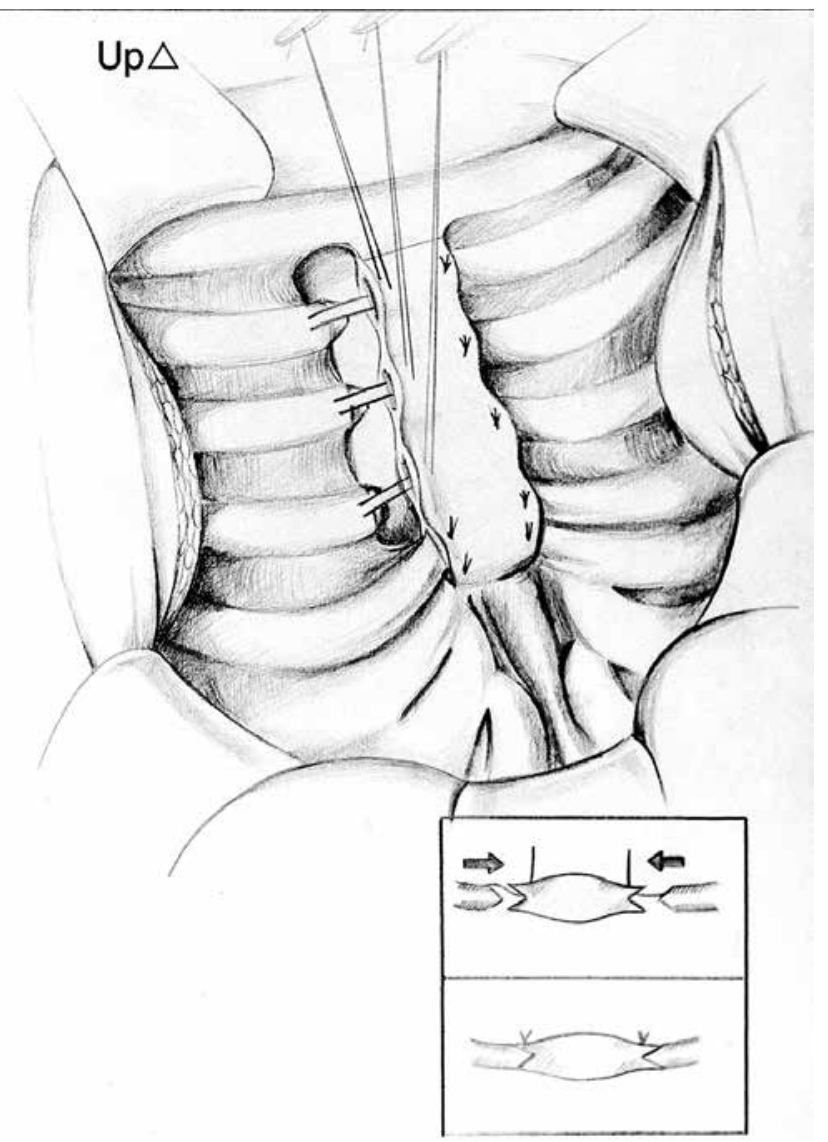

Figure 1. Illustration presenting modification at the stage of cutting the cartilages to form the shape of a blade with wedge-shaped hollows at the edges, into which the cartilages will be inserted. Knotted sutures form a "ladder-like" scaffold on the anterior lamina of the sternum, providing support for further muscle reconstruction

Table I. Long-term results after modified Ravitch procedure

\begin{tabular}{lcccc} 
Chest & \multirow{2}{*}{$\begin{array}{c}\text { Number } \\
\text { deformity }\end{array}$} & \multicolumn{3}{c}{ Result } \\
\cline { 3 - 5 } $\begin{array}{l}\text { of patients } \\
\text { Pectus }\end{array}$ & 57 & Very good & Good & Unsatisfactory \\
excavatum & & $75.4 \%)$ & $10(17.5 \%)$ & $4(36.4 \%)$ \\
\hline $\begin{array}{l}\text { Pectus } \\
\text { carinatum }\end{array}$ & 11 & $7(63.6 \%)$ & $3(27.3 \%)$ & $1(9.1 \%)$ \\
\hline Mixed form & 4 & $4(100 \%)$ & $0(0 \%)$ & $0(0 \%)$ \\
\hline Total & 72 & $54(75 \%)$ & $13(18 \%)$ & $5(6.9 \%)$ \\
\hline
\end{tabular}

5-6 days, and in the case of surgical wound dehiscence, the hospitalization time was extended to 14-21 days.

The medical history obtained from the subjects revealed additional burdens, such as chest pain in 4 cases, fatigue compared to peers in 11 patients, as well as dyspnoea in 5 subjects. Scoliosis of the thoracic spine, which is a defect accompanying pectus excavatum, was regularly monitored by a specialist in 7 cases, while it was left untreated in 4 patients. Nine subjects with allergy received specialist care on a regular basis. Eleven patients had a positive family history of the defect.

The results of surgical treatment are presented in Table $\mathrm{I}$ and Figures 2 and 3. In patients with pectus excava- 

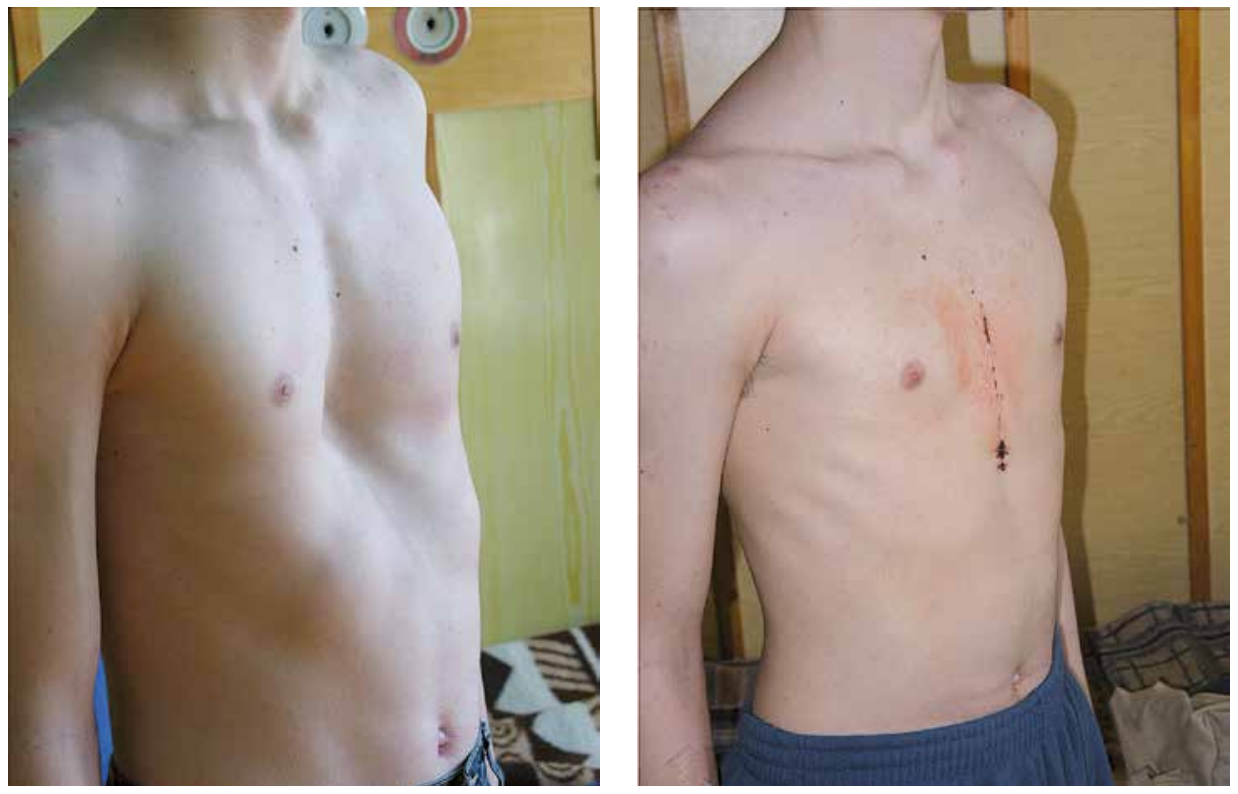

Figure 2. Photograph of the patient's anterior chest wall before and after pectus excavatum surgery

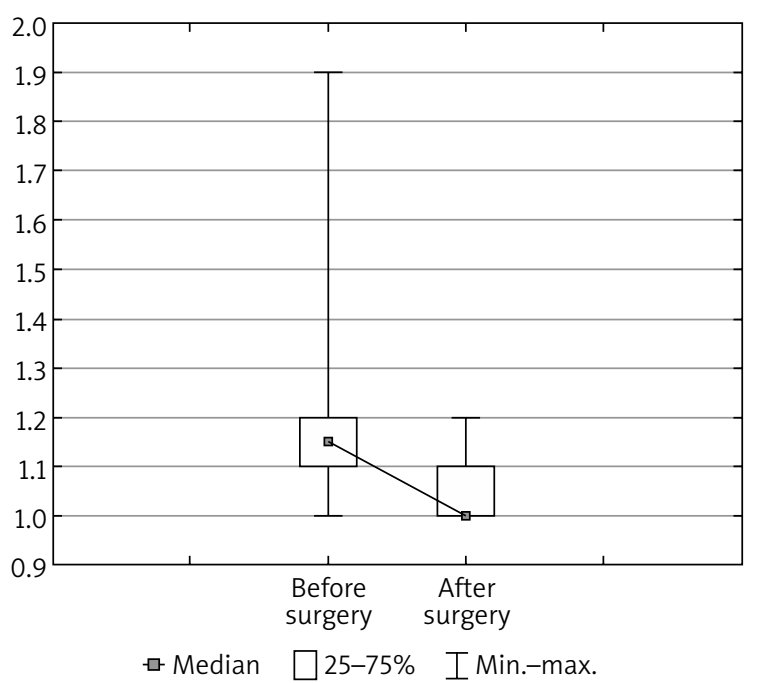

Figure 3. Kopera-Krol index before and after the modified Ravitch procedure in patients with pectus excavatum $(n=57$; Wilcoxon test: $Z=4.93, p=0.000001)$

tum, the median pre-operative $\mathrm{K}-\mathrm{K}$ value of 1.15 (1.10; 1.20) dropped to $1.00(1.00 ; 1.10)$ post-operatively - the result was statistically significant $(Z=4.93 ; p=0.000001)$. A very good result of the pectus excavatum operation was achieved in $43(75.4 \%)$ subjects. A lower score, i.e. a good effect in this category, was noted in 10 (17.4\%) cases, and 4 (7\%) patients assessed the result as mediocre. The same qualification used in the subjects with pectus carinatum indicates a very good result in 7 (63\%) out of 11 cases. A good result was reported in 2 (18.1\%) patients. Dissatisfaction was reported in $1(9.0 \%)$ case. A small group of patients with the mixed form had very good long-term results.

The complications of the postoperative wound were reported in 13 (18\%) patients, including 6 patients with swelling and redness around the surgical wound, sometimes superficial serous leakage; 7 (5.5\%) patients had complete or partial dehiscence of the surgical wound. Putting layered seams on the wound followed by continuous subcutaneous suturing eliminated this complication with no impact on the previous cosmetic effect of the operation. The use of vacuum devices in patients with dehiscence of the surgical wound allowed the treatment time to be significantly shortened.

One patient with relapse eligible for reoperation did not give consent for the procedure.

Hospitalization ends with a reminder of the principles of safe rehabilitation; for 6 weeks the patient should avoid contact games and physical exercises with arm swings and all kinds of bodybuilding. After this period, the patient gradually returns to normal functioning. The postoperative control examination period was 12 months dating from the surgery. In case of any doubts about the surgery, the patient could consult his/her surgeon at any time.

\section{Discussion}

The condition is usually noticed when the body enters the period of turbulent puberty; therefore, the question arises whether deformation of the anterior chest wall is really a congenital problem. This does not exclude cases where the deformity is manifested just after birth. The defect may also occur in members of the same family. In our study, this was the case in 11 patients, regardless of the type of defect, and this is too little to support the thesis. The congenital nature is often confirmed by the medical history, but only after a long problem-focused investigation.

Choosing the most appropriate age for surgical treatment is controversial [15]. According to some authors, early intervention, i.e. between the age of 3 and 5 , brings the best results; later, due to physiological stiffening of the chest wall, the operation becomes more and more difficult. This view raises many doubts, all the more so that the conse- 
quences of too early surgery described by Haller [16] are very disturbing, as evidenced by the average age of the patients (14.6 years old for boys and almost 13 years old for girls). Our experience indicates this age range as the optimal time for surgery, which should be performed before the end of ossification. Additionally, this approach makes it possible to restore previously limited interactions with peers, for example during physical education classes, though paradoxically the latter trigger self-criticism. Children driven by a desire to change their appearance exert more and more pressure on parents and caregivers, and thus the topic is more and more often raised in family conversations.

Debates are held on which of the correction methods is the most advantageous from the point of view of the patient, costs and even workload of the people involved. Comparative analyses cover the open Ravitch procedure and the popular minimally invasive Nuss procedure. Each of them has advantages and disadvantages. The comparisons included symptoms, the age of patients, duration of an operation, hospitalization time, and finally the effectiveness of pain management. According to some authors, the results suggest no difference between the Nuss and Ravitch procedures for paediatric patients [17-19], while others indicate the advantage of the Nuss procedure [20,21].

Dehiscence of the surgical wound accompanied by infection is not very frequent in paediatric patients after pectus excavatum repair $[17,22]$. In our study, it occurred in $5 \%$ of the subjects. A significant improvement was reported after placing and suturing the gentamicin plate in the operating field on the surface of the sternum before closure of the surgical wound. The use of vacuum devices was another milestone in the elimination of undesirable effects [23]. As a consequence, hospitalization time significantly decreased, and patents' opinions on the quality of the operations improved. The cause of post-operative recurrence is still difficult to identify. In our study, one relapse was reported. We still do not know its cause, and the patient did not agree to reoperation.

Evading postoperative medical recommendations is difficult to confirm, because negligence and flaws in this respect are carefully concealed by the patients, who have a tendency to blame other people and independent circumstances for their failure. Thus, self-discipline can be a factor determining long-term outcomes.

Very good results of one-year follow-up conducted in $54(75 \%)$ subjects prove the effectiveness of the method. This is reflected in a keen interest in our procedure and a demand for this type of surgery, which has been performed at the department since 1999.

\section{Conclusions}

The technique we propose is a one-time, definitive corrective operation to treat deformation of the anterior chest wall in children and adolescents. Good long-term results make the procedure suitable to be used more frequently in all types of anterior chest wall deformities.

\section{Disclosure}

The authors report no conflict of interest.

\section{References}

1. Ravitch MM. The operative treatment of pectus excavatum. Ann Surg 1949; 122: 429-434.

2. Ochsner A, DeBakey M. Chone-chondrosternon: report of a case and review of the literature. J Thorac Cardiovasc Surg 1939; 8: 469-511.

3. Adkins PC, Blades B. A stainless-steel strut for correction of pectus excavatum. Surg Gynecol Obstet 1961; 113: 111-113.

4. Rehbein F, Wernicke HH. The operative treatment of the funnel chest. Arch Dis Child 1957; 32: 5-8.

5. Robicsek F. Marlex mesh support for the correction of very severe and recurrent pectus excavatum. Ann Thorac Surg 1978; 26: 80-3.

6. Fonkalsrud EW, Follette D, Sarwat AK. Pectus excavatum repair using autologous perichondrium for sternal support. Arch Surg 1978; 113: 1433-1437.

7. Bhatnagar V, Sharma N, Dhua A, Jana M. Surgical correction of pectus excavatum using a rib graft strut following excision of costal cartilages. J Indian Assoc Pediatr Surg 2019; 24: 252-256.

8. Fibla JJ, Molins L. Minimally invasive treatment of pectus excavatum. Minerva Chir 2016; 71: 38-45.

9. Mak SM, Bhaludin BN, Naaseri S, Di Chiara F, Jordan S, Padley S. Imaging of congenital chest wall deformities. Br J Radiol 2016; 89: 20150595.

10. Międzynarodowa Statystyczna Klasyfikacja Chorób i Problemów Zdrowotnych. Rewizja dziesiąta. Tom I. Wydanie 2008 Uniwersyteckie Wydawnictwo Medyczne „Vesalius”.

11. Kowalewski J, Barcikowski S, Żołyński K. Wyniki kosmetyczne leczenia operacyjnego chorych z lejkowatą klatką piersiową. Pol Przegl Chir 1992; 64: 389-395.

12. Tomaszek L, Fenikowski D, Gawron D, Komotajtys H. Comparative efficacy of continuous infusion of bupivacaine/fentanyl and ropivacaine/fentanyl for paediatric pain control after the Ravitch procedure and thoracotomy. A prospective randomized study. Biomed Pap Med Fac Univ Palacky Olomouc Czech Repub 2019; 163: 366-373.

13. Manworren RC, Stinson J. Paediatric pain measurement, assessment, and evaluation. Semin Pediatr Neurol 2016; 23: 189-200.

14. Tomaszek L, Fenikowski D, Komotajtys H, Gawron D. Ropivacaine/fentanyl vs. bupivacaine/fentanyl for pain control in children after thoracic surgery: a randomized study. Pain Manag Nurs 2019; 20: 390-397.

15. Jaroszewski D, Notrica D, McMahon L, Steidley DE, Deschamps C. Current management of pectus excavatum: a review and update of therapy and treatment recommendations. J Am Board Fam Med 2010; 23: 230-239.

16. Haller Jr JA, Colombani PM, Humphires CT, Azizkhan RG, Loughlin GM. Chest wall constriction after to extensive and too early operation of pectus excavatum. Ann Thorac Surg 1996; 91: 1618-1624.

17. Kanagaratnam A, Phan S, Tchantchaleishvilli V, Phan K. Ravitch versus Nuss procedure pectus excavatum: systematic review and meta-analysis. Ann Cardiothorac Surg 2016; 5: 409-421.

18. Antonoff MB, Erickson AE, Hess DJ, Acton RD, Salzman DA. When patients choose: comparison of Nuss, Ravitch, and Leonard procedures of primary repair of pectus excavatum. J Pediatr Surg 2009; 9: 1113-1119.

19. Nasr A, Fecteau A, Wales PW. Comparison of the Nuss and the Ravitch procedure for pectus excavatum repair: a meta-analysis. J Pediatr Surg 2010; 45: 880-886.

20. Johnson WR, Fedor D, Singhal S. Systematic review of surgical treatment techniques for adult and pediatric patients with pectus excavatum. J Cardiothorac Surg 2014; 9: 25.

21. Mao YZ, Tang S, Li S. Comparison of the Nuss versus Ravitch procedure for pectus excavatum repair: an updated meta-analysis. J Pediatr Surg 2017; 52: 1545-1552.

22. Kauffman J, Benzie AL, Snyder CW, Danielson PD, Chandler NM. Short-term outcomes after pectus excavatum repair in adults and children. J Surg Reseach 2019; 244: 231-240.

23. Aramini B, Morandi U, De Santis G, Brugioni L, Stefani A, Ruggiero C, Baccarani A. Wound complication after modified Ravitch for pectus excavatum a case of conservative treatment enhanced by pectoralis muscle transposition. Int J Surg Case Rep 2020; 66: 322-325. 